\title{
La imagen del mundo en las culturas prehispánicas
}

Eduardo Badía Serra ${ }^{1}$

Recibido en Agosto 2011, aprobado en Octubre 2011

\begin{abstract}
Resumen
Este artículo esboza las imágenes del mundo que tenían nahuas, mayas, quechuas, y se comparan con la cosmovisión de la Grecia antigua. El autor busca demostrar que en todas esas cosmovisiones subyace un riguroso esfuerzo racional, para explicarse el universo.
\end{abstract}

Palabras claves

Imagen del mundo, culturas prehispánicas, sabiduría, filosofía presocrática.

\begin{abstract}
This article outlines the ideas that the Nahuas, Mayans, and Quechuas had about the world, and compares them to the view of the world in Ancient Greece. The author aims to prove that in these particular views there is an underlying rigorous effort to rationally explain the universe.
\end{abstract}

Keywords

Worldview, pre-Hispanic cultures, knowledge, PreSocratic philosophy 


\section{1.- INTRODUCCIÓN UN CONTEXTO GENERAL DE SITUACIÓN}

Se trata en este artículo, de exponer las imágenes del mundo que tenían las culturas prehispánicas a la llegada de los españoles. No se pretende dar una completa descripción de dichas culturas en los diferentes aspectos de su desarrollo; ello es de sobra descrito en la amplia bibliografía que se dispone, en los muchos estudios e investigaciones hechos alrededor del tema, y en las fuentes o Códices aceptados como fuentes para su estudio, (Códices o libros indígenas prehispánicos, códices indígenas coloniales, textos indígenas escritos en náhuatl y trascritos en alfabeto de códices sacerdotales indígenas, y representaciones iconográficas acompañadas de signos glíficos en monumentos prehispánicos), y en la fuerte tradición que de alguna manera se ha mantenido y ha permitido conocer el pensamiento y la vivencia de dichos pueblos. Dicha tradición que incluso ahora puede observarse y palparse todavía en algunas regiones de mesoamérica y el área andina. Más bien, el objetivo es describir su concepción del mundo, y resaltar algunos paralelismos que se han dado entre ella y la astronomía y cosmología de la Grecia antigua. Adicionalmente, exponer algunas bases filosóficas sobre las cuales dichas visiones fueron sustentadas, (pluralidad de esencias, mundos jerárquicos, noción del movimiento, ideas sobre la perfección y la imperfección, necesidad de explicación del mundo sobre bases racionales, necesidad lógica de una fundamentación universal, determinismo y fatalismo cósmicos, etc., etc.).

Fueron muchos y diversos los pueblos que existieron en América antes de la llegada de los españoles. Sin embargo, a dicha llegada, puede decirse ${ }^{2}$, que cinco grandes culturas poblaban ese amplio continente: Los Pieles Rojas o Tribus del Norte, que agrupaban un amplio espectro de pueblos al norte del Río Grande: Iroqueses, Onondagas, Esquimales, Atapascos, Algoquinos, Mustakis, Dakotas o Sioux; los Maya-quiché, que habitaban en la región de Yucatán, Campeche, Tabasco, Chiapas, Guatemala, Tehuantepec y parte de la actual Centroamérica; los Aztecas o Mexicas, pobladores del Anahuac, que eran producto de una larguísima evolución de anteriores civilizaciones localizadas al sur de los Estados Unidos, México y parte de Centroamérica, como los Comanches, los Sonoras o Chihuahuas, los Olmecas, los Chichimecas, los Toltecas, los Tlaxcaltecas, etc., que ahora se conocen genéricamente como cultura Nahuatl; los Incas del sur, en Perú, Bolivia y Ecuador, fundamentalmente, expresión última de la civilización Quechua; y los Fueguinos en Chile. Para efectos de este trabajo, se considerarán únicamente las visiones de tres de ellas; Nahuatl-Aztecas, MayasQuichés y Quechuas-Incas, por considerarse que son las que obtuvieron un mayor desarrollo cultural, desarrollo que de alguna manera se mantenía al arribo de los conquistadores. 
Según Rosemblatt ${ }^{3}$, la población en América a 1492 era de unos 13 millones de habitantes. Esta cifra es considerada baja por otros autores, algunos de los cuales otorgan sólo a los Incas una población no menor de ocho millones. Cifras igualmente conservadoras hablan de poblaciones del orden de los 20 millones de habitantes. Como quiera que sea, es importante reseñar que la población prehispánica al momento del descubrimiento era apreciable. Para efectos justamente ilustrativos, se incluye a continuación la población por regiones de acuerdo al autor citado:

\begin{tabular}{|c|c|c|}
\hline 1 & Norteamérica (Norte del Río grande & $1,000,000$ \\
\hline 2 & $\begin{array}{l}\text { México, Centroamérica y Antillas } \\
\text { México } \\
\text { Haití y Santo Domingo } \\
\text { Cuba } \\
\text { Puerto Rico } \\
\text { Jamaica } \\
\text { Antillas Menores } \\
\text { Centroamérica }\end{array}$ & $\begin{array}{r}5,600,000 \\
4,500,000 \\
100,000 \\
80,000 \\
50,000 \\
40,000 \\
30,000 \\
800,000\end{array}$ \\
\hline 3 & $\begin{array}{l}\text { Suramérica } \\
\text { Colombia } \\
\text { Venezuela } \\
\text { Guayanas } \\
\text { Ecuador } \\
\text { Perú } \\
\text { Bolivia } \\
\text { Paraguay } \\
\text { Argentina } \\
\text { Uruguay } \\
\text { Brasil } \\
\text { Chile }\end{array}$ & $\begin{array}{r}6,785,000 \\
850,000 \\
350,000 \\
100,000 \\
500,000 \\
2,000,000 \\
800,000 \\
280,000 \\
300,000 \\
5,000 \\
1,000,000 \\
600,000\end{array}$ \\
\hline
\end{tabular}

Significa entonces que Aztecas y Maya-Quichés constituían unos 5.3 millones, y que Incas, unos 3.3 millones. Estas tres grandes culturas sumaban así unos 9 millones de personas al arribo de Colón.

3 A. Rosemblatt, Población Indígena de América, revista Tierra Firme, núm. 8, pp. 110. Madrid, España, 1935 
Por su parte, señala José Alcina Franch ${ }^{4}$, que investigaciones recientes de Cook, Simpson y Borah, de la Escuela de Berkeley, asignan a los aztecas las poblaciones que se indican:

\begin{tabular}{|c|c|}
\hline 1519 & $25,200,000$ \\
1532 & $16,800,000$ \\
1549 & $6,300,000$ \\
1568 & $2,600,000$ \\
1580 & $1,900,000$ \\
1605 & $1,000,000$ \\
1620 & 800,000 \\
\hline
\end{tabular}

El dato de población de la América “India“ a 1492 es inseguro. Los autores discrepan mucho, tanto que esta población se extrema, por ejemplo, en los cálculos del padre Las Casas (3, De la destrucción de las Indias), como se deduce en opinión de Clavijero 5 , para quien incluso los españoles debieron "importar" indios desde Jamaica y otras antillas con el objeto de suplir necesidades de mano de obra.

Las culturas prehispánicas eran producto de visiones múltiples de la realidad. Dentro de sus códigos simbólicos se ubicaban aspectos tan diversos como religiosos, científicos y técnicos, artísticos y literarios, ambientales, arquitectónicos, urbanísticos, etc. El tiempo y el espacio eran fundamentales para su desarrollo, y los calendarios, elevados a la máxima expresión de exactitud y precisión, fueron objeto de posteriores estudios que les otorgaron el mayor de los avances. Asimismo, los prehispánicos nunca separaron el conocimiento en áreas diferentes y delimitadas, manteniendo en ello una visión de totalidad. Esto va a reproducirse indudablemente en su cosmología, en la cual se mezclarán elementos diversos de los antes citados, sobre todo, los mítico-religiosos, los relativos a la espacio-temporalidad, una fuerte visión cromática de la realidad, y los impresionantes elementos arquitectónicos de los cuales perduran todavía monumentales expresiones.

4 José Alcina Franch, Los Aztecas, Biblioteca de Historia, Talleres Gráficos Peñarola, S. A., Madrid, España

5 Francisco Javier Clavijero, Setima disertación, Historia Antigua de México, libro X, segunda edición. Editorial Porrúa, S. a., México, 1968 


\section{2.- IMAGEN DEL MUNDO EN LOS NÁHUATL}

Los náhuatl plasman el carácter fundamental de su cosmovisión en una manifestación que acontece por primera vez en América: La arquitectura. Analicemos esto rápidamente a la luz de su historia:

Los períodos de la cultura náhuatl son, gruesamente expresados, tres:

Un período Arcaico, preclásico, que cubre desde el año 2000 a.C. hasta el año 100 a.C. Son obras de este período, por ejemplo, la unidad ceremonial de Cuicuilco, llamada Pirámide de Cuicuilco, la cual tiene unos 140 metros de diámetro, y en la que aparecen ya dos elementos estéticos claramente representativos de la arquitectura mexicana, el círculo, para los griegos la forma geométrica perfecta, y el color.

Un período Clásico, que se extiende desde los años 100 a.C. hasta el 950. La ciudad de Teotihuacan, en el Valle de México, es de este período. Teotihuacan, que es una ciudad y no un centro ceremonial, ocupado por una reducida población permanente, es un rectángulo alargado de unas 200 hectáreas. Se encuentra a una altura de $2280 \mathrm{msnm}$. Su nombre significa Lugar de la Apoteosis, (en náhuatl, teotia significa adorar). El eje de la ciudad es la Calle de los Muertos, la cual corre en un sentido sur-norte, a lo largo de unos 2 kilómetros, y con unos 45 metros de ancho.

La obra más importante, y probablemente la más antigua de Teotihuacan, es la Pirámide del Sol, enorme masa de unos 50,000 metros cuadrados de base y $1,250,000$ metros cúbicos de volumen. Fue probablemente construida entre los años 100 y 250. Otra de las grandes obras es la Pirámide de la Luna, que, junto con la Ciudadela, al extremo sur de la Calle de los Muertos y con una orientación este-oeste y una base de 400 x 400 metros, constituirían el núcleo grueso de la ciudad.

Una comparación de las dos grandes pirámides del Sol y de la Luna muestra lo siguiente:

\begin{tabular}{|l|l|l|}
\hline Pirámide & del Sol & de la Luna \\
Base & $225 \times 225$ metros & $150 \times 130$ metros \\
Número de cuerpos & 5 & 5 \\
Altura & 63 metros & 42 metros \\
Forma & Truncada de cuerpos \\
Orientación & $\begin{array}{l}\text { Truncada de cuerpos escalonados } \\
\text { Eje } \\
\text { Altura de la Cúspide } \\
\text { Dirección de la Calle de }\end{array}$ & $\begin{array}{l}\text { norte-sur } \\
\text { Perpendicular a la de los Muertos } \\
\text { La misma }\end{array}$ \\
\hline
\end{tabular}


En el período clásico aparecen ya la escritura y el calendario.

Un tercer período lo constituye el llamado Período Militarista, que abarca desde el año 950 hasta la llegada de los españoles en 1521.

Sobre esto del gran desarrollo de la cosmología náhuatl, y como ha sucedido con la historia de la cultura prehispánica, la dispersión de opiniones lleva, desafortunadamente, a contradicciones y contraposiciones. El sabio Barberena ${ }^{6}$ dice al respecto que la que pomposamente llaman 'astronomía tolteca' no es más que una maraña de leyendas mitológicas [...]respecto a los astros [...] Sin embargo, no deja de reconocer grandes logros obtenidos por dichos pueblos en estos conocimientos. Cita, por ejemplo, tomando del examen que hace Humbolt del Códice Telleriano-Remense, y de las investigaciones del Dr. Forstemann respecto al Códice de Dresde, la gran aproximación entre el período de revolución sinódica de Venus establecido por los toltecas, 584 días, y el establecido por la moderna astronomía, 583 días- 22 horas -6 minutos- 40 segundos. Gallo y Anfossi ${ }^{7}$, por ejemplo, otorgan a la astronomía y a la astrología náhuatl, y en general, a la prehispánica, gran desarrollo: Desarrollaron sistemas complicados y útiles de observación astronómica, de medición del tiempo, de registro de eventos; llegaron incluso a conocer algunas constelaciones, como Escorpión, Toro, las Pléyades, a la que llamaban Tianguiztli, es decir, abundancia de gente, tianguis, y por supuesto, los mismos planetas conocidos en el resto del mundo a la época. Similar posición asume repetidamente la Carneige Institution of Washington, cuyos arqueólogos revelan acuciosas observaciones astronómicas no solo de los nahuatl sino también del resto de naciones que conformaban el mundo prehispánico. Los grandes adelantos, por supuesto, comprobados en el observatorio llamado Caracol, situado en Chichen-Itzá, cuyas visuales desde su sala de observación coincidían con la posición del Sol en los equinoccios, y desde otros puntos permitían conocer la máxima declinación positiva de la Luna en la época de los equinoccios, la declinación mínima del satélite, y también el equinoccio mismo.

Se reconoce a los toltecas el ser los iniciadores del método de contar los años que usaron las naciones cultas del Anahuac, lo cual suponía muchas observaciones y conocimientos precisos de astronomía.

Refiere Clavijero ${ }^{8}$, que según Boturini, estos toltecas corrigieron el exceso de casi seis horas del año solar sobre el civil que usaban, intercalando un día cada

6 S. I. Barberena, Historia de El Salvador, Época antigua y de la Conquista, Tomo I, Ministerio de Educación, Dirección General de Publicaciones, Tercera Edición, San Salvador, El Salvador, C. A., 1977

7 J. Gallo, E. Anfossi, Cosmografía, Editorial Progreso, S. A., Séptima Edición, $1^{\text {a }}$. Reimpresión, México, 1980

8 F. J. Clavijero, Historia Antigua de México, libros I a VI, Segunda edición, Editorial Porrúa, S. A., México, 1968 
cuatro años, lo cual hacían ya antes de la era cristiana. También corresponde a los toltecas la pintura del gran libro divino, o teoamoxtli, que habla del origen de los indios, de su dispersión después de la confusión de las lenguas en Babel, de sus peregrinaciones en Asia, de las primeras poblaciones que tuvieron en América, de la fundación de Tula, de su astronomía, de su calendario, de su mitología, y de tantas otras cosas. En esas pinturas, precisamente, pueden identificarse cometas, eclipses y muchos otros fenómenos del cielo.

Apunta siempre Clavijero siguiendo a Boturini, que en algunas pinturas describen el eclipse solar acaecido en el día de la muerte de nuestro Redentor, en el año 7 tochtli, cuestión comprobada por muchos historiadores españoles, los cuales pudieron establecer además que para estos pueblos, a la fecha del nacimiento de Jesús habían transcurrido 5199 años desde la creación del mundo, lo que es precisamente coincidente con la cronología de la iglesia romana siguiendo el cómputo de los Setenta.

Y más aún, es de alguna manera compartido el hecho de que los toltecas tenían clara e inequívoca noticia del diluvio universal, de la confusión de las lenguas y de la dispersión de las gentes, cuestión esta que todavía puede comprobarse por relación directa de los indígenas que todavía habitan en Guatemala y en El Salvador. Para Clavijero, sin embargo, este pretendido conocimiento del diluvio universal no es otra cosa más que el producto de la confusión que sufrieron estos pobladores al identificar este diluvio con el río Colorado, al que siempre veían en sus viajes desde las regiones del sur del Anahuac hasta las regiones del norte en Culiacán.

Los toltecas construyeron la extraordinaria pirámide de Cholula, ciudad esta en la que había un templo por cada día del año, y sobre los cuales los españoles edificaron sendas iglesias, que al momento aún se encuentran. Cholula es conocida como la ciudad que tiene una iglesia para cada día. Se dice que con la pirámide de Cholula quisieron simular los toltecas a la torre de Babel, cuestión esta muy discutida y dudosa. Hay incluso quienes atribuyen a los toltecas la construcción de las pirámides de Teotihuacan, opinión esta muy compartida y justificada. Clavijero', anota que Torquemada, que fue uno de los mejores cronistas de la pintura y de los manuscritos de la Nueva España, pero a quien se atribuyen también muchas imprecisiones, fue uno de los que creyeron que los toltecas fueron los arquitectos de dichas obras.

La expresión arquitectónica de Teotihuacan es la de la rigidez y sequedad de la línea recta, la de la organización del espacio externo conformado por volúmenes arquitectónicos, y la de un carácter exclusivamente arquitectónico y urbanístico. Predominan las formas simples y las líneas rectas. Contrasta

9 F. J. Clavijero, Historia Antigua de México, libros I a VI, Segunda edición, Editorial Porrúa, S. A., México, 1968 
lo anterior con la expresión de Tula, obra tolteca cuya característica es la decoración y la escultura, y cuya expresión arquitectónica es el lujo y la riqueza. Los toltecas, cuyo origen se pierde en la historia, van identificándose como tales a partir del año 511, extendiéndose su reinado por cuatro o cinco siglos, hasta el 1052, año de la muerte de su último emperador, Topilzin, y situándose su mayor desarrollo y florecimiento en los siglos X-XI. Su presencia corresponde a lo que ahora es el Estado de Hidalgo.

Lo anterior permite vislumbrar ya una concepción del espacio en esta rica cultura náhuatl, en la que está contenida su visión del mundo, pues, como se ha dicho, los náhuatl integran su cosmovisión a su concepción espacio-temporal y no al revés. Siempre de acuerdo con la cosmología náhuatl, es el movimiento solar el que dicta la orientación de todos los astros. Esta orientación ofrece una particularidad interesante, porque el eje occidente-oriente, que por representar la trayectoria de la encarnación y de la liberación, fue adoptado por toda Mesoamérica, está modificado en 17 grados hacia el norte. Después de minuciosas investigaciones, se llegó a descubrir que la causa de esta distorsión proviene de que la pirámide está dirigida hacia el punto donde el sol se oculta el día de su pasaje por el cenit del lugar.

Esta versión de su cosmovisión en las obras arquitectónicas de los náhuatl se reproduce y reconfirma repetidamente al examen de muchas de sus obras monumentales, de lo cual se hablará un poco en próximas páginas.

Los náhuatl integran el universo en dos espacios, el espacio horizontal y el espacio vertical, esto es, la tierra y el universo. El espacio horizontal se extiende en un plano hacia los cuatro rumbos del mundo. En la versión generalmente aceptada, se concibe como un gran disco de tierra rodeado de agua y situado en el centro del universo. Es, pues, como puede verse, la tierra, el centro del universo. Cada uno de los rumbos del mundo señala una función determinada, a saber: El oeste corresponde al país blanco, a la casa del sol, país de las mujeres, de la fecundidad y de la vida; el este es el país rojo, el rumbo de la luz, de la fertilidad y la vida, cuyo símbolo es la caña; el norte es el país negro, el país de los muertos, frío y desierto, cuyo símbolo es el pedernal; el sur es el país azul, el país del rumbo incierto, cuyo símbolo es el conejo, que nadie sabe por donde va a saltar.

Estos cuatro rumbos rodean a Tlaltipac, la Tierra, que se encuentra en el centro, rodeada a su vez por un anillo de agua, Cem-Anahuatl. El Sol se mueve, saliendo del este, pasando por el norte, viajando hacia el oeste y retornando al este por el sur. El Sol pasa, pues, de la fertilidad y la vida hacia la fecundidad y la vida, encontrando en su recorrido al desierto, al frío y a la muerte en el norte, llegando al oeste, al país de la fecundidad y de la vida, retornando a la fertilidad de la caña pasando por un rumbo incierto que se encuentra al sur. 
A este espacio horizontal, que es la Tierra, los Náhuatl agregan un espacio vertical, que corresponde a su universo. El espacio vertical lo conciben como formado por dos regiones separadas por el espacio horizontal. Es decir, este espacio vertical estaría dividido en dos por el espacio horizontal. Las dos regiones que constituyen el espacio vertical son: Las Trece Regiones Cósmicas, y las Nueve Regiones de los Infiernos.

Las trece regiones cósmicas, a su vez, se estructuran en tres diferentes planos, como se muestra en el siguiente esquema:

$1 \quad$ Plano Físico(Plano de los Astros)

Región de la Luna

Región de las Estrellas

Región del Sol

Región de Venus

Región de los Cometas

2 Plano de los Colores

La Noche (lo negro)
El Día (lo azul y lo verde)
Las Tempestades
Lo Blanco
Lo Amarillo
Lo Rojo

3 Plano Metafísico

Mansión Omeyocan o

Región 1

Mansión de la Dualidad

Región 2

Tapia Rodríguez ${ }^{10}$ por su parte, describe así esos trece cielos y el mundo de los muertos, que luego pasan a ser descritos también:

En el primer cielo hay una estrella con faldilla que es hembra y otra estrella con penacho que es macho. Son los 'guardianes del firmamento'.

En el segundo cielo hay mujeres que no tienen carnes, sólo hueso, y se les llama 'mujeres de mal agüero'; ellas están ahí para cuando el mundo se acabe, esto es, cuando desaparezcan los dioses y Texcatlipoca se robe al Sol, porque serán las encargadas de comerse a los hombres.

En el cielo tercero están los cuatrocientos hombres que hizo Texcatlipoca, y que son de cinco colores diferentes: amarillos, negros, blancos, azules y

10 J. Tapia Rodríguez, Leyenda y misterio de los aztecas, Edicomunicación, S. A., Barcelona, España, 1977 
colorados. Estos hombres están ahí como guardianes del propio cielo.

En el cuarto cielo están todos los géneros de aves, y desde ahí vienen a la tierra.

En el quinto cielo están las serpientes de fuego, las mismas que hizo el dios del fuego, y están ahí para crear los cometas y todas las señales del firmamento.

En el sexto cielo están todos los aires, y los dioses los pusieron ahí para que movieran todas las cosas.

En el séptimo cielo está todo lleno de polvo y piedras, y desde allí bajan a la tierra.

En el octavo cielo es donde se juntan todos los dioses.

En el noveno cielo se mueve el señor de nuestra carne y su mujer, Tonacatecuhtli y Tonacacíhuatl, y de ahí en adelante nadie sabe lo que hay en el resto de los cielos, ni siquiera los dioses, porque estos cielos están reservados para el señor de nuestra carne y sus creaciones, o para lo que nadie sabe.

Los muertos, por su lado, van, dice siempre Tapia Rodríguez:

A Mictlan, al infierno, donde están el señor y la señora del inframundo, y donde hay nueve infiernos, los que mueren de muerte natural, de enfermedad sencilla, sin honor y sin lucha, en muerte inútil.

A Xotchitlapan, los niños que morían en la cuna, que no son culpables de su muerte.

A Tlalocan, los enfermos de enfermedad grave o contagiosa, o los muertos por la fuerza de los dioses, por accidente natural.

A la Casa del Sol, los guerreros, hombres y mujeres, las mujeres que mueren de parto, los sacrificados a los dioses, los prisioneros de guerra.

Los señores más elevados y principales se convierten en nubes, nieblas, pájaros, joyas, y toda cosa hermosa de riqueza valor.

Como se ve, esta versión de Tapia Rodríguez difiere de la anterior, que es la clásica y casi universalmente aceptada, pero lo hace sin perder el sentido y la esencia de los contenidos, que son básicamente los mismos.

Siguiendo con la versión clásica con la que antes hemos descrito la región de los trece cielos, el espacio vertical hacia arriba, por su lado, abajo del espacio horizontal, esto es, debajo de la Tierra, se constituye, como hemos visto con Tapia, el Espacio Vertical de las nueve Regiones de los Infiernos. Estos son planos 
cada vez más profundos, en los cuales los muertos (los descarnados, según eran llamados), deben morar cuatro años venciendo pruebas para poder entonces descansar por completo.

En la Mansión de la Dualidad, esto es, en el Plano Metafísico, superior de las trece regiones cósmicas, Omeyocan, se encuentra la fuente de la generación y de la vida, y en ella mora Ometeotl. Ometeotl se desdobla en cuatro fuerzas, sus hijos, que constituyen los cuatro elementos, tierra, agua, aire y fuego. Ninguno de estos elementos existe por sí mismo sino los cuatro, y por ello, dicen los náhuatl, su condición es precaria e inestable. Estos cuatro elementos provocan las luchas cósmicas, simbolizadas por los odios entre Texcatlipoca y Quetzalcoatl. Son fuerzas en tensión y sin reposo, que llevan en sí el germen de la lucha.

Cada período correspondiente a estas cuatro fuerzas en tensión genera una edad y da origen a un Sol. Han pasado ya cuatro soles, estamos en el quinto sol, el Sol del Movimiento, el de la Armonía. Pero el destino final de esta edad será, sin duda, un cataclismo, que se dará al romperse la armonía lograda.

Como se ve, si bien, como señala Johanna Broda, citada por Alcina Franch ${ }^{11}$ en los aztecas se denota la visión estructurada en la que los antiguos mesoamericanos combinaban sus nociones de cosmología relacionando tiempo y espacio en un conjunto sistemático, cuestión esta que parece no tener discusión, también pienso que no es discutible que las visiones relatadas son de alguna manera diversas, aunque sosteniendo el sentido y la esencia de la concepción, como ya he dicho. Para reforzar lo anterior, quisiera referir cómo Alcina Franch, en su magnífico trabajo, entiende la cuestión de los trece cielos y de los nueve infiernos:

Dice este historiador y arqueólogo sevillano, que el mundo azteca era concebido como un espacio o territorio de forma rectangular, o cuadrado, cuyos límites eran los cuatro puntos cardinales, y en cuyo centro de hallaba un agujero o punto de comunicación entre el inframundo y el cielo, que constituía, por eso, el quinto punto cardinal o el quinto rumbo. Por encima de la superficie terrestre se hallaban nueve o trece cielos, confusión esta en la que no se ponen de acuerdo las fuentes, como también no se ponen de acuerdo en la forma en que deben contarse o colocarse, ya que si para unos los cielos se ordenan sucesivamente del primero al decimotercero, de manera que este último se encuentra en el lugar más alejado de la superficie terrestre, para otras fuentes el más elevado es el séptimo, siendo cada cielo como un escalón en una pirámide, hallándose el primero al este, allí por donde nace el Sol, y el decimotercero al oeste, allí

11 J. A. Franch, Los Aztecas, Biblioteca de Historia, Talleres Gráficos Peñarola, S. A., Madrid, España 
por donde se oculta y pasa al inframundo. Los nueve inframundos se ordenarían de manera parecida, de modo que el sol, en su viaje nocturno, iría pasando por cada uno de los escalones de otra pirámide, esta invertida, y con sólo nueve pisos o inframundos, de los que el quinto sería el más alejado de la superficie terrestre.

Los cielos e inframundos, según el Códice Vaticano Latino 373, se ordenarían en la secuencia que se expone:

\section{Cielos}

$\begin{array}{ll}13 \text { y } 12 & \text { Omeyocan, lugar de la dualidad } \\ 11 & \text { Teotl Tlatlahuca, o Dios que está rojo } \\ 10 & \text { Teotl Cosauhca, o Dios que está amarillo } \\ 9 & \text { Teotl Iztacca, o Dios que está blanco } \\ 8 & \text { Iztapalnacazcayan, lugar que tiene esquinas de lajas de } \\ 7 & \text { obsidiana } \\ 6 & \text { Ilhuicatl xoxouhca, cielo que está verde } \\ 5 & \text { Ilhuicatl yayauhca, cielo que está negruzco } \\ 4 & \text { Ilhuicatl namalhacoca, cielo donde está el giro } \\ 3 & \text { Ilhuicatl huixtotlan, cielo-lugar de la sal } \\ 2 & \text { Ilhuicatl Tonatiuh, cielo del Sol } \\ 1 & \text { Ilhuicatl Citlalicue, Cielo de Citlalicue, la falda de las } \\ & \text { estrellas } \\ \text { inframundos } & \text { Ilhuicatl Tlalocanihuan Metztli, Cielo de Tlalocan y la Luna }\end{array}$

$\begin{array}{ll}1 & \text { Tlaltipac, la Tierra } \\ 2 & \text { Apanohuayan, el paradero del agua } \\ 3 & \text { Tepetl monanamicyan, lugar donde se encuentran los cerros } \\ 4 & \text { Itztepetl, cerro de obsidiana } \\ 5 & \text { Itzohecayan, lugar del viento de obsidiana } \\ 6 & \text { Pancuecuetlacayan, lugar donde tremolan las banderas } \\ 7 & \text { Temiminaloyan, lugar donde es muy flechada la gente } \\ 8 & \text { Itzmictlan apochcalocan, lugar de obsidiana de los muertos, } \\ & \text { lugar sin orificio para el humo }\end{array}$

\begin{tabular}{|l|l|l|l|}
\hline \multicolumn{5}{|c|}{ Los soles náhuatl son: } \\
\hline 4 Tigre & la Tierra & 676 años & $13 \times 52$ \\
\hline 4 Viento & el Aire & 364 años & $13 \times 28$ \\
\hline 4 Lluvia & el Fuego & 312 años & $13 \times 24$ \\
\hline 4 Agua & el Agua & 676 años & $13 \times 52$ \\
\hline 4 Movimiento & el Sol actual & & \\
\hline
\end{tabular}


Como se ve, los cuatro soles han durado un período de años siempre múltiplo de 13, estando ahora el universo en su quinto Sol, el sol del Movimiento, que corresponde a la época del ombligo.

De acuerdo con lo anterior, la secuencia de la Creación nahuatl es la siguiente:

1 Ometeotl se desdobla en sus cuatro hijos, las cuatro fuerzas cósmicas, Tierra, Agua, Fuego y Aire;

2600 años después de creadas las cuatro fuerzas cósmicas, estas crearon el Fuego y el Sol;

3 Luego hicieron a un Hombre y a una Mujer (el hombre y el maíz);

4 Luego hicieron los Días, los Meses (20 días), y los Años (18 meses, 360 días);

5 Luego hicieron el Lugar de los Muertos, y a los dioses del Infierno (Mictlantecuhtli y Mictecacihuatl, marido y mujer), y les pusieron el él;

6 Luego hicieron los Cielos y las Aguas;

7 Luego hicieron el Agua, un gran Pez, Cipactli, como caimán, y de este pez hicieron la Tierra.

Y así pusieron en marcha la historia del Universo.

El concepto del tiempo se encuentra perfectamente relacionado en los náhuatl en su calendario. Como se sabe, el calendario es una de las mejores y más claras expresiones de la cosmovisión de un pueblo. En la cultura náhuatl, como en la maya y en la quechua, esto se comprueba claramente. Algo se ha dicho ya de ello en las páginas anteriores, pero considero adecuado ampliar suficientemente este punto.

Distinguían los náhuatl, cuatro diferentes edades del mundo, y en ellas cuatro distintos soles. La I Atonatiuh, Sol o Edad del Agua, que va desde la creación del mundo hasta el diluvio universal o tiempo en el que el sol y los hombres se acabaron. La II Tlaltonatiuh o Edad de la tierra, que va desde el diluvio universal hasta la destrucción de los gigantes y los grandes terremotos en que pereció el segundo sol. La III Hecatonatiuh, o Edad del Aire, desde la destrucción de los gigantes hasta los grandes huracanes que acabaron con el tercer sol y con todos los hombres. La IV Tletonatiuh, o Edad del fuego, desde la última reparación del linaje humano hasta que el cuarto sol y la tierra sean consumidas con fuego. Pero, inusualmente, resultó que al principio del nuevo siglo el dios fuego suspendió su voracidad y prorrogó el término del mundo. 
Dos siglos conformaban una edad, o, como decía, una vejez de 104 años. Los años tenían cuatro nombres característicos: Tochtli, Acatl, Técpatl y Calli, esto es, conejo, caña, pedernal y casa. El primer año del siglo era 1 conejo, el segundo, 2 caña, el tercer, 3 pedernal, el cuarto, 4 casa, el quinto, 5 conejo, y así sucesivamente hasta el 13 avo.

El año constaba de 365 días dividido en 18 meses de 20 días a los cuales sumaban cinco días inútiles o nemontemi. Al parecer, el año náhuatl comenzaba en nuestro correspondiente 26 de febrero, y cada cuatro años intercalaban un día, por lo cual este año lo comenzaban el día 14 de febrero, por los 13 días que correspondían al ciclo de 52 años.

Desearía reseñar aquí los nombres de los meses y de los días del año náhuatl:

Nombres de los meses

1 Atlacahualco

2 Tlacaxipehualiztli

3 Tozoztontli

4 Hueitozoztli

5 Toxcatl

6 Etzalcualiztli

7 Tecuilhuitontli

8 Hueitecuilhuitl

9 Tlaxochimaco

10 Xocohuetzi

11 Ochpaniztli

12 Teotleco

13 Tepeilhuitl

14 Quecholli

15 Panquetzaliztli

16 Atemoztli

17 Tititl

18 Izcalli
Nombres de los días

1 Cipactli, lagarto

2 Ehecatl, viento

3 Calli, casa

4 Cuetzpalin, lagartija

5 Coatl, culebra

6 Miquiztli, muerte

7 Mazatl, ciervo

8 Tochtli, conejo

9 Atl, agua

10 Itzcuintli,cuadrúpedo

11 Ozomatli, mono

12 Malinalli, hierba

13 Acatl, caña

14 Ocelotl, tigre

15 Cuauhtli, águila

16 Cozcacuauhtli, ave

17 Olin tonatiuh,movimiento del sol

18 Tecpatl, pedernal

19 Quiahuitl, lluvia

20 Xochitl, flor

No son aplicables mecánicamente las anteriores denominaciones. La complejidad del calendario y del cómputo del tiempo en los náhuatl es muy grande, y de alguna manera varía de nación en nación. Pero lo expresado anteriormente nos permite hacer una relación de similitud múltiple con nuestra cultura: De nuevo, 
los cuatro elementos como ejes motores de la concepción del mundo terreno, por así decirlo, como elementos dialécticos de la lucha y el movimiento, como divinidades, como guías de la espacialidad y de la temporalidad del universo; la increíble similitud entre la duración de los años y su distribución; las inexactitudes entre ambas formas de medir el tiempo, y las muy similares correcciones que ambas culturas efectuaban. De estos paralelismos se hablará en el apartado 5 de este trabajo.

Otra cuestión importante de reseñar en la cultura náhuatl es su concepción del alma, y la forma en que esta visión se relaciona e imbrica con su visión del mundo en general. Esta concepción del alma se sostuvo dentro de todos los pueblos o naciones que constituyeron esa gran cultura. Los bárbaros, u otomíes, por ejemplo, creían que el alma fenecía con el cuerpo; el resto de naciones creían, al contrario, que era inmortal, inmortalidad que incluso reconocían en los brutos o animales. A las almas correspondían diferentes lugares y destinos: las de los soldados que morían en la guerra, de los prisioneros en poder de los enemigos, de las mujeres que morían de parto, iban a la Casa del Sol, que imaginaban Señor de la Gloria, en donde pasaban una vida deliciosa, viajando todos los días del oriente al occidente y viceversa; las de los que morían por accidente o por una enfermedad no natural, las de los niños y las de los sacrificados a los dioses iban a un lugar fresco y ameno que llamaban Tlalocan, en donde vivían una vida de abundancia; y las de los que morían de enfermedad natural iban al infierno, - Mictlan, lugar situado en el centro de la tierra, en donde sufrían a causa de la sola pena de morar en la oscuridad.

Igual de interesante es su concepción del diluvio universal que ya he comentado. Del diluvio se salvaron, según los mexicas, un hombre llamado Cocox o Teocipactli, y una mujer llamada Xochiquetzal, los cuales viviendo al pie del monte Colhuacán tuvieron muchos hijos, todos nacidos mudos, hasta que una paloma desde lo alto de un árbol les infundió las lenguas tan diferentes que no se entendían los unos y los otros. Los tlaxcaltecas, por su lado, decían que los hombres quedaron convertidos en monos, pero poco a poco fueron recobrando el habla y la razón.

Hay una sorprendente similitud de la cosmovisión náhuatl con la astronomía y la cosmología de la Grecia antigua. A este paralelismo se hará referencia en el tema 5 de esta monografía. Tan singular visión del mundo, puede sintetizarse entonces en los términos siguientes:

Dicha visión no puede enfocarse aisladamente, esto es, sobre la base de una categorización individual, sólo geométrica, o solo matemática, o solo real, o solo abstracta, o sólo intuitiva, o sólo lógica. El espacio y el tiempo para ellos, ni son un todo físico, ni son un todo lógico, ni son un todo abstracto, ni son un todo real. Son simplemente, un todo, un todo que recoge una concepción mítico- 
religiosa-científica-cultural-tradente, en fin, un todo en el que se muestra una sola esencia aunque diversamente predicada. Porque las culturas prehispánicas, y esto ha sido ya mencionado en la introducción, no separaban los diferentes campos del conocimiento, tal y como nosotros lo acostumbramos hacer. Para ellos existía el conocimiento, no los conocimientos; existía el conocimiento como uno, y en este conocimiento se reúne, unitariamente aunque con gran diversidad de predicados, toda la realidad, dentro de la cual se encuentran, por ejemplo, los predicados espacio-temporales.

Hay en la realidad categorías dialécticas, científicas, míticas, religiosas. La realidad es como una versión actualizada de la tradición, la que enseñan los tlamantinime, sus filósofos, vertida en un ámbito cultural producto de una realidad física y de una realidad lógica. La visión del mundo debe recoger esa realidad y reproducirse en ella. Por ello sus pirámides tratan de enfocar las trece regiones cósmicas, que culminan en el plano metafísico donde mora Ometeotl, y en cuyo vértice, en cuyo ápice, un día, y solo un día, de acuerdo a su propio calendario, el Sol se proyectará sin sombra en el cenit, cada año náhuatl, en una versión tal de perfección que ha asombrado a todos los visitantes y estudiosos de esa cultura.

En la misma forma, sus ciudades reproducen su visión del mundo. Alcina Franch dice que la división tripartita de la ciudad de Tenochtitlan, hoy la ciudad de México, esa misma que sorprendió a Cortez cuando la divisó desde Río Frío, visión que reprodujo Diego Rivera en su bellísimo mural, correspondía exactamente a los cuatro rumbos de la división del mundo azteca:

\section{Divinidad}

$\begin{array}{llll}\text { Rumbo } & \text { correspondiente } & \text { Barrio Prehispánico } & \text { Barrio Colonial } \\ \text { Noroeste } & \text { Quetzalcoatl Blanco } & \text { Cuepopan } & \text { Santa María } \\ \text { Noreste } & \text { Texcatlipoca Negro } & \text { Atzacoalco } & \text { San Sebastián } \\ \text { Suroeste } & \text { Texcatlipoca Azul } & \text { Moyotlán } & \text { San Juan } \\ \text { Sureste } & \text { Quetzalcoatl Rojo } & \text { eopan } & \text { San Pablo }\end{array}$

El quinto rumbo, el central, naturalmente, corresponde al recinto ceremonial, en cuyo centro se hallaba el Templo Mayor, dedicado a Tlaloc y a Huitzilopochtli.

Había, pues, un principio cosmogónico que regía para la construcción de las ciudades, cuestión en la que abunda Moreno, y Larrauri y Mercado, citados siempre por Alcina Franch.

Los náhuatl conformaban, a la llegada de los españoles, el pueblo azteca. Fuertes seguidores de la tradición y sostenedores de la ancestral cultura, los aztecas dispusieron migrar, recorriendo el altiplano, o hacia el rumbo del Pacífico, y proyectaron su cultura fuertemente evolucionada a los pueblos de 
Mesoamérica, principalmente a los de la amplia y prolongada costa sur en el Pacífico, esto es, la zona sur de Guatemala (Cotzumalhuapa), y prácticamente la mitad del territorio salvadoreño, (Tazumal). Siguieron la ruta de los volcanes y llegaron a Cuzcatlán. Hasta allí pudieron llegar. La conquista los detuvo.

\section{3.- IMAGEN DEL MUNDO EN LOS MAYAS. EL PUEBLO MAYA-QUICHE.}

A la visión náhuatl del mundo, nada tiene que envidiar la expresión que en el mismo sentido eternizó la increíble y misteriosa cultura maya. Esta cosmovisión fue cambiando progresivamente, al igual que en los náhuatl, y con dichos cambios fue volviéndose más compleja. De acuerdo con la tradición, el mundo fue creado, destruido y recreado por lo menos tres veces antes de llegar a su concepción final, que es la que ha sido conocida.

Los mayas fueron arquitectos en primera línea, si bien no desmerecen en ninguna de las versiones con que expresaron de manera tan diversa sus instituciones, vale decir, la pintura, la escultura. Y es que en ellos la arquitectura, más que necesidad de un mundo físico, es necesidad de una expresión cultural, en la que se enlazan siempre unitariamente aunque diversamente predicadas, costumbres, mitos, tradiciones, leyendas, la ciencia, la técnica, en fin, todas las formas posibles del hacer humano.

También fueron reconocidos como grandes astrónomos, a grado tal que se les llamó los caldeos de América.

Estos mayas colosales eran también supersticiosos y muy ligados a creencias y tradiciones. Por ejemplo, actuaban en ellos números cabalísticos, en su caso, el 13: 73 veces 13 baktunes es el Gran Ciclo. Una Era es 4 Ahau, 8 Cimku, Fin del Baktun 13. El mundo fue creado para los mayas en el año 3373 a.C. Hay algunas opiniones que cifran esta fecha en el año 3114 a.C., correspondiente siempre al día 4 ahau de su calendario (en coincidencia, el mundo fue creado para los hebreos en el año 3761 a.C.).

Los mayas organizan la historia del universo en grandes ciclos o eras cósmicas en las que el universo se recrea y se destruye, con infinidad de ciclos menores que rigen la existencia del mundo y de los hombres, determinando su destino. Es, su universo, como se verá luego, un cosmos constituido por tres grandes niveles con armónicas formas geométricas, pleno de colores y de naturaleza, en constante devenir, y en el cual el hombre ocupa el centro, como otro axis mundi. 
El relato cuenta ${ }^{12}$ y considero importante reseñarlo aquí de alguna manera, que lo primero que hizo Maíz revelado (el primer padre al final de la tercera creación), fue "alzar el árbol del mundo", llamado Wakah-Chan o Cielo Elevado. Así separó el cielo de la tierra y estableció el centro de todo lo creado, el "eje del cosmos“. Este árbol era representado como una ceiba gigantesca, (a veces como una exuberante caña de maíz cargada de mazorcas maduras), llamada de múltiples maneras además de Cielo Elevado (Primer árbol precioso, Árbol del Cielo, Bosque Elevado, Plataforma del Cielo, etc.). Se dice que en los primeros momentos de la creación, el cielo estaba acostado sobre la tierra, de tal manera que la luz no existía. En este lugar, conocido como Cielo Acostado, los dioses auxiliares, bajo la supervisión del Primer Padre, colocaron tres piedras, las tres piedras fundamentales de la Creación, que fueron símbolo del sacrifico, de la muerte y de la resurrección del Primer Padre. Después el Primer Padre entró en el cielo y lo convirtió en el cielo Elevado, opuesto recíproco del Cielo Acostado, en el que construyó una casa de ocho pisos con la cual ordenó todo el universo superior: El mundo en que vivimos y los astros celestes. El techo de esta casa era conocido como Domo del Cielo o Casa del Norte, y hasta ahí llegaban las ramas del Árbol de la Creación, la Ceiba Madre. Posteriormente, el Primer Padre impuso al cielo un movimiento circular, y echó a andar en él a las constelaciones. Todo lo que él hacía estaba escrito en las estrellas, para que los hombres pudieran leerlo. En total, pues, el cielo tenía trece pisos, daba hospedaje a los astros e incluso a algunos animales solares como el venado y las aves de colorido plumaje.

Otro relato, que tomo de la misma fuente, reproduce la visión anterior de la forma siguiente: La tierra era imaginada como un enorme cocodrilo sobre el que los hombres de la cuarta generación se desplazaban sin saberlo, y en cuyo dorso nacía la vegetación. Sobre este cocodrilo construyeron los mayas sus hermosos palacios de acuerdo con el movimiento celeste que el Primer Padre imprimió al cielo en el momento de la creación. Bajo este cocodrilo estaba el inframundo, dividido en nueve pisos, y en cuya parte inferior se encontraba el Reino de Xibalbá. En el inframundo vivían los muertos en compañía de los animales nocturnos o peligrosos, como murciélagos, buhos, jaguares y ciertas deidades conocidas como Bolontikú. El mismo día en que el Primer Padre alzó el Árbol del Mundo, estableció también las ocho direcciones del cosmos, que se desplegaron sobre la tierra como kan tzuk, kan yuk (cuatro divisiones, cuatro esquinas, o los cuatro puntos cardinales y las cuatro esquinas del universo), a las que agregaban una quinta en el centro, y a cada cual correspondía un color (blanco en el norte, amarillo en el sur, negro en el oeste y rojo en el este), y un Bacab (uno de tantos seres celestes que cargaba sobre sus espaldas una porción del cielo para sostenerlo durante toda la eternidad). En el centro, considerado el ombligo del mundo, estaba ubicado el árbol del mundo y las tres piedras de 
la creación. Este ombligo del mundo era un cordón umbilical, representado como una cuerda con cabeza de serpiente que emergía del vientre de Nun-Yal$\mathrm{He}$, el Primer Padre, y con la cual los hombres se comunicaban con los dioses y la fuente de la vida.

Pero al relato mítico y fantasioso en alguna manera, transmitido de muchas formas y coloridos, corresponde realmente una unitaria y bien fundamentada cosmovisión, que se reproduce a continuación:

Se considera ${ }^{13}$ que la cosmovisión maya es original, y en ella sólo extrínsecamente caben las clasificaciones lógicas occidentales; pero a la vez no es absolutamente distinta de las cosmovisiones occidentales. Hay semejanzas esenciales, como la idea de que el universo tiene una temporalidad ordenada, que se encuentra ya en los filósofos griegos, o la de una dualidad en el espíritu del hombre entre una parte racional y consciente y otra irracional e inconsciente. Los mayas parten de que el universo se origina y existe en virtud de poderes sobrenaturales, y por ello a veces reducen toda su visión del mundo a religión. En este universo hay tres grandes instancias, como partes integrantes de una misma realidad: los dioses, el mundo y el hombre, cuestión esta que muestra una semejanza singular con el pensamiento filosófico de la antigua Grecia, e incluso, con la posterior tradición de la filosofía cristiana-escolástica.

Parten también de una concepción dinámica del universo, en la cual este es un devenir ordenado, con un logos inalterable susceptible de ser conocido, comprendido y manejado por el hombre. Ello los obligó a desarrollar notables conocimientos astronómicos y matemáticos, así como al desarrollo de una extraordinaria cronología. En la misma forma, denota un sentido no determinista ni fatalista en su pensamiento, puesto que otorgan al hombre la necesaria libertad para manejar su propia cotidianidad y su futuro. Esto les hace a su vez preocuparse de manera central por conocer y sistematizar el devenir, para anticipar el futuro con base al pasado, lo cual, de alguna manera, los llevó a ser proféticos.

El cosmos es, para ellos, un devenir ordenado, proveniente de un estatismo caótico e indiferenciado, o materia prima acuática en estado de reposo en la que todo está confundido. Por ello, dicen, se dan los diluvios como destrucciones con vuelta al caos. No hay en el origen del cosmos, un inicio absoluto, ex-nihilo, y el futuro es una sucesión creciente de creaciones y destrucciones, por lo que el universo, para los mayas, es infinito.

13 M. de la Garza, El pensamiento maya, en Filosofía Iberoamericana en la época del encuentro, edición de Laureano Robles, Enciclopedia iberoamericana de filosofía, Ediciones Trotta, Consejo Superior de Investigaciones Científicas, Quinto Centenario, Madrid, España, 1992 
Para los mayas, los cuatro puntos cardinales dan una orientación cromática del mundo, y son las voluntades de la tierra. Su símbolo es la Ceiba, en forma tal que:

La Ceiba, roja en el oriente, tiene por símbolo un pedernal rojo-calabaza.

La Ceiba, blanca en el norte, tiene por símbolo un pedernal blanco -calabaza.

La Ceiba, negra en el poniente, tiene por símbolo un pedernal negrocalabaza.

La Ceiba, amarilla en el sur, tiene por símbolo un pedernal amarillocalabaza.

Eran así tan importantes los cuatro puntos cardinales, a los que llamaban chacs, que los consideraban dioses, aunque menores, y por ello los adoraban.

Los mayas atan, en la misma forma que lo hacen los náhuatl, su cosmovisión con su concepción espacio-temporal. El universo se da, también en ellos, en el espacio y en el tiempo. Reconocen tres mundos:

El Mundo Ínfero de Ah Mucen Cab.

El Mundo de las divinidades de Ox Lahun Ti-Ku, en el que existen trece dioses y trece divisiones.

El Mundo Subterráneo de Bolon Ti-Ku, en el que existen nueve dioses y nueve divisiones.

Es sorprendente observar las tremendas similitudes entre los náhuatl y los mayas. Aquí pueden verse de nuevo las trece regiones cósmicas y las nueve regiones de los infiernos del espacio vertical náhuatl. A ello, los mayas suman un mundo ínfero, el mundo que es apenas el punto de partida, probablemente, y del cual hacen una manifiesta y continua referencia, lo que denota su importancia dentro de su pensamiento. Este inframundo lo dividían, como los náhuatl, en regiones especiales en las que habitaban los muertos según el tipo de muerte que les había sobrevenido.

Ah Mucen Cab partió del mundo ínfero para vendar los ojos de los trece dioses celestes, quienes fueron cogidos por los nueve dioses de los infiernos. Pero después de la destrucción amanece otra época y se alza el primer árbol blanco en el norte, y "se levantó el arco del cielo", y el primer árbol negro, y el primer árbol amarillo, y el primer árbol rojo "en señal de la destrucción de abajo". 
Resalta la profundidad, la riqueza, la melodía y la armonía, de la concepción, pero sobre todo, lo unitario de la misma.

El universo maya es un cubo, precisamente la forma perfecta de Platón, dividido horizontalmente en tres planos, el plano astronómico, el plano físico y el plano espiritual, que vienen a representar la triple naturaleza de Hunab$K u$, y seccionado verticalmente por los cuatro puntos cardinales singularmente coloreados. El centro del cubo es Hunab-Ku, ser único, superior, bisexuado para engendrarlo todo.

El cubo es la construcción ideal que todo lo contiene, incluso a los dioses, y está dividido en cuatro partes que son la proyección tridimensional de sus respectivas bases cuadradas, y en las diversas secciones del cubo se dan cuadrángulos, así sean todos simétricos, quizá con la intención de lograr una sólida estática por medio del equilibrio matemático y de fuerzas mágicas expresadas en números cabalísticos que amarran los vértices.

Este concepto del universo se explica aún más utilizando algunos de los elementos matemáticos mayas: Los ocho octantes del cubo arrojan doce vértices que unidos al punto central del sistema dan 13, precisamente su número cabalístico. Los trece puntos de los cuatro octantes suman 52. El ciclo ritual maya, 18980 días, dividido por 52 años, da como resultado 365, lo que corresponde a nuestra duración anual. A su vez, 20 días en ciclos de 13 hacen el Tzolkin (260 días), que para generar el Ciclo Ritual de 18980 días tiene que multiplicarse 73 veces. Por ello, el Tzolkin da 73 vueltas. Como puede verse, hay similitud entre el calendario maya y el azteca. Igual que los aztecas, dividieron el año en 18 meses de 20 días cada uno, más cinco días complementarios. Al año solar lo completaron con la creación del katun o ciclo de 20 años de 365 días cada uno, y otro de 52 años solares.

Los mayas reproducen en sus ciudades a su universo cúbico: El plano cuadrilátero es la ciudad, su superficie. Esta superficie es tetrapartida por dos calles en ángulo recto (los cuatro puntos cardinales), que son extendidas a toda la nación y a toda la tierra. El eje principal es oriente-poniente, ligeramente desviado 4 a 5 grados hacia el noroeste, (17 a 20 grados en el caso de Yucatán).

Cada punto cardinal está representando una particular categoría espacial, y a su vez, una particular categoría vital y cósmica.

Para los mayas, el Pensamiento se encuentra en la Pirámide Mayor, siempre al Este. Y desde su plataforma, el pensamiento sigue con los ojos el rumbo de los luceros y la huella de los hombres para ponerlos en concordancia y fecundidad. 
Esa es entonces la ciudad maya, que a la par que resuelve una necesidad física de vivienda y convivencia, refleja y contiene, eterniza, todos sus elementos culturales. El maya, indudablemente, vive en su ciudad, su ciudad es su vivencia, refleja su vivencia; el maya siente su ciudad, ella le expresa a él y a su vez se ve expresado en ella. Y este reflejo de relación hombre-ciudad no es otra cosa que la reproducción en ella del universo maya, de una cosmovisión en la que el hombre es agente-actor irremediablemente.

En dicha cosmovisión pueden anotarse algunas consideraciones: el plano rectangular es un elemento de proporción. El paralelepípedo tridimensional es el elemento de proporción como proyección del rectángulo en el espacio. El cubo es el elemento expresivo más simple, la forma cristalina más simple y perfecta. El campo es el sustento. Las ciudades son la paz. Las pirámides son la alegría, y se levantan cuatro al principio de cada camino.

Los mayas tuvieron un importante y complejo conocimiento de los cielos, en función de cuya astronomía establecían sus ciclos agrícolas. A su manera dispusieron también de una especie de gnomon (dos varas o hilos cruzados formando una equis), como punto fijo de observación celeste. Establecieron ciclos lunares, solares y venusinos, observando las conjunciones estelares. Tenían un año civil casi perfecto, de 365 días (exactamente, de 365.24.20 días). Midieron el ciclo solar con un error menor de 17.28 segundos en relación con el año trópico y la invención del uso del cero y el valor posicional de los signos. Supieron calcular la duración de la lunación. Crearon un complejo y preciso sistema de calendarios, compuesto por varios calendarios sincronizados, que incluye una fecha era: 13.0.0.0.0, 4 ahau 8 cumhu, que corresponde en nuestro sistema al 12 de agosto de 3113 a.C., que equivale al día del comienzo del tiempo (el Quinto Sol de los náhuatl, precisamente), y gracias a la cual lograron por ejemplo fijar con absoluta precisión un día situado 400 millones de años hacia el pasado. Conocieron otros planetas además de Venus, así como numerosas constelaciones y estrellas, como la Estrella Polar, a la que llamaban Xaman Ek, las Pléyades, a las que llamaban Tzab (cascabel de serpiente), y Géminis, a la que llamaban tortuga (Ac). Conocieron los eclipses, y los simulaban a una bestia tratando de comerse al Sol, cosa que si lograba provocaría el fin del mundo. Tal concepción era utilizada por los sacerdotes para atemorizar al pueblo, pues ellos sí sabían exactamente lo que era un eclipse.

Concedían una gran importancia a ciertos simbolismos. El cuatro, por ejemplo, era un rico simbolismo: Cuatro puntos cardinales, cuatro fases de la luna, cuatro estaciones, cuatro momentos principales del día, cuatro edades de la vida humana, cuatro sectores de cada nivel cósmico; dioses que se conciben como uno y cuatro simultáneamente; en cada rumbo, cuatro ceibas que sostienen el cielo y son árboles de la vida, sobre las cuales se posan pájaros sagrados; y 
cuatro abejas, cuatro pedernales, cuatro pavos, cuatro flores, cuatro frijoles y cuatro maíces en los rumbos del mundo; cuatro dioses antropozoomorfos sosteniendo la pirámide celeste, siendo los animales relacionados a esos dioses, la tortuga, el caracol, la araña y la zarigüella.

Para los mayas ${ }^{14}$, el tiempo era un dinamismo, el dinamismo intrínseco del espacio y de todos los seres que lo habitan. No concebían el tiempo, pues, como un concepto abstracto, sino dinámico y real, lo cual les permitió dar al universo temporalidad cíclica.

Otra idea fundamental en los mayas es la de la dualidad de contrarios, la pugna de contrarios cósmicos, vida-muerte, noche-día, cielo-inframundo, masculinofemenino, bien-mal, como motores que producen el cambio.

¿Por qué desaparecieron los mayas? Existen dos versiones: La primera habla de un misterio al que se sobrepone una crisis ambiental; la segunda sostiene que no hubo tal colapso del pueblo maya, y que simplemente entraron en un proceso de reorganización y cambios paulatinos que culminó, precisa y finalmente, con la llegada de los españoles.

Los mayas desaparecieron misteriosamente ... Pero aún siguen ahí.

\section{4.- IMAGEN DEL MUNDO EN LOS QUECHUA. EL PUEBLO INCA.}

Los Incas, hijos del Sol, fueron el pueblo que desarrolló el imperio más grande en la América prehispánica. Tanto es así que a la luz de la historia y de los vestigios de sus obras todavía existentes, los estudiosos de su cultura se sorprenden de lo que en ella van encontrando y no se explican algunas veces como pudieron alcanzar tales niveles de desarrollo. Cusco, Machu Picchu, las líneas de Nazca, son importantes y vivientes testimonios de ello. Como consecuencia de que en su ámbito no existía el concepto de la creación del mundo, los andinos decían haber salido de sus lugares de origen con todos sus adornos de cabeza y armas. Este lugar de origen era, según algunos, dos lagunas, y según otros, el mar, volcanes o cerros nevados. En ellos, es el mito el que atribuye a Wiracocha la creación del universo y del mundo.

Según una tradición, el rey Sol, Inti o Wiracocha, se sintió mal con estos pueblos de la tierra, y decidió enviarles sus dos hijos para que les enseñaran cómo crear su propia cultura. De tal manera que envió a su hijo Manco Capac y a su hija Mama Ocllo hacia las profundidades del lago Titicaca, desde donde ascendieron a la superficie del agua. Ellos se casaron y fundaron la ciudad Inca de Cusco,

14 M. de la Garza, El pensamiento maya, en Filosofía Iberoamericana en la época del encuentro, edición de Laureano Robles, Enciclopedia iberoamericana de filosofía, Ediciones Trotta, Consejo Superior de Investigaciones Científicas, Quinto Centenario, Madrid, España, 1992 
"el ombligo del mundo". Otra versión, que Luis Alberto Sánchez ${ }^{15}$ considera "más científica", habla de que de una cueva de cuatro ventanas (Tampuctacco, la cueva o posada de las ventanas), salieron cuatro parejas, una de cada ventana, siendo la principal la de Ayar Manco y Mama Ocllo; los cuatro varones eran hermanos, los Ayar; buscando una zona propicia para sus ambiciones, echaron a andar siempre en la misma dirección del Sol, hasta que llegaron a las inmediaciones de Cusco, el ombligo del mundo. Por ello, los pueblos preincaicos ubicaban el nacimiento del Sol en una isla de dicho lago. La leyenda cuenta que en dicho lugar, el Sol eligió su primer descendiente humano, Manco Capac (Primer Inca), y construyeron un santuario luego al lado de una gran formación rocosa llamada Piedra Sagrada (Titikala).

Como en los mayas y en los náhuatl, hay en los incas el reconocimiento del acontecimiento del diluvio universal, a partir del cual, en los incas, se dan cuatro generaciones de indios: La primera generación, Pacarimoc Ruma, gente esta del amanecer-nacer-aparecer, muy atrasada y extremadamente elemental; la segunda generación, Variruna, que ya muestra un desarrollo aunque aún elemental, agricultura, viviendas construidas sustituyendo a las cuevas, vestido; la tercera generación, Purunruna, ya de un desarrollo aceptable en cuanto a sus necesidades naturales, vestido, vivienda, alimento, con una primera estructura social, pueblos regidos por reyes y capitanes, leyes y mandamientos, religión, diversiones, y un desarrollo de infraestructura, caminos, señales; y una cuarta generación, Aucarunas, de gente guerrera emigrando a las partes altas, construcción de fortalezas, alto grado de confusión y degeneración social, algún nivel de anarquía, pero de gran riqueza económica. Estas cuatro edades duraron cerca de 5300 años, hasta que la última generación es conquistada y dominados sus territorios por los incas

Como siempre, no existe una versión completamente aceptada en relación con la autenticidad del pensamiento de estas culturas prehispánicas. Lo mismo sucede con los quechuas, y particularmente con su pueblo inca. Para María Luisa Rivera ${ }^{16}$ por ejemplo, si bien no hubo una filosofía incaica como tal, sí hubo una estructura de pensamiento genuina y original, aun reconociendo la posibilidad de que se diera en parte por los puntos de contacto que pudieran tener con las expresiones del pensamiento universal.

De la misma manera que con los nahuas y con los mayas, en los incas toda esta estructura de pensamiento y su realidad misma giraba sobre Dios (Wiracocha), el mundo, (Pacha), y el hombre (Runa).

15 L. A. Sánchez, Historia General de América, tomo I. Sexta edición corregida y puesta al día, Ediciones Ercilla, 1956

16 M. L. Rivera de Tuesta, El pensamiento incaico, en Filosofía Iberoamericana en la época del encuentro, edición de Laureano Robles, Enciclopedia iberoamericana de filosofía, Ediciones Trotta, Consejo Superior de Investigaciones Científicas, Quinto Centenario, Madrid, España, 1992. 
Algunos elementos que confirman el amplio desarrollo del pueblo Inca se citan a continuación, como preámbulo a la exposición de la visión que del mundo tenían los pueblos quechuas ${ }^{17}$.

Los Incas tenían un entendimiento avanzado del entorno celeste y lo ocupaban regularmente para actividades públicas y religiosas, que hacían girar, como todo lo prehispánico, alrededor de ciertos simbolismos, el cuatro, por ejemplo, siendo de nuevo uno de los más importantes en los incas. El Sol era la primera deidad venerada, y la mayoría de sus ceremonias eran conducidas y relacionadas con objetos celestes, el Sol sobre todo, y la agricultura. Son conocidos los festivales de Inti Raymi y Capac Raymi, que ocurrían respectivamente a los solsticios de junio y diciembre, cuando el Sol frena su carrera en el horizonte $e$ inicia su regreso. Debe recordarse que este cambio de acimut de la salida y puesta del Sol en el horizonte es un hecho clave para todas las astronomías antiguas.

Los Incas construyeron sistemas de pilares para permitir al pueblo monitorear el paso del tiempo al ver el sol pasar cerca de ellos en el horizonte. Hay divergencias en cuanto a la cantidad de pilares y sus ubicaciones, pero al menos existieron ocho en el horizonte de Cuzco, dos marcando el solsticio de verano en el cerro Quiancalla, cuatro en el cerro Picchu (dos de ellos indicando el tiempo para plantar), y dos en el cerro Chinchincalla. Estos pilares tendrían que haber sido bastante grandes, unos cinco metros de altura, y sólidos, para ser vistos perfilados en el horizonte a una distancia de algunos kilómetros. Todavía existían cien años después de la conquista. Sólo quedan hoy ruinas de dos de ellos arriba de la ciudad de Urubamba, a 35 kilómetros de Cusco.

El Sol del solsticio de junio se ponía entre dos pilares situados en una colina adyacente a Titikala llamada Tikani, de los cuales quedan sus fundaciones y el primero a 0.5 metros de altura.

Los cronistas describen también el uso del gnomon por los incas, el cual, entre otras funciones, permitía definir con facilidad el paso del Sol por el cenit (fenómeno que ocurre solamente en la región tropical). Este evento tenía probablemente una importancia significativa por indicar la presencia del dios solar en el centro del cielo, con su influencia máxima de poder. Existían también las llamadas Ushnus, o plataformas sagradas, que eran lugares de observación del Sol. La idea principal detrás del concepto de ushnu era una apertura en la tierra donde el agua, la lluvia por ejemplo, entraba. Los ushnus podían tener uno o varios de los siguientes tres elementos: Un sillón de oro para que se sentara el Inca durante las ceremonias; un gnomon para realizar la

17 M. Boccas, Astronomía Incaica: el misterio sigue ....., http://www.ctio.Noao-edu/-boccas/ astro2000-2.html. 
observación del Sol o marcar con exactitud un punto de observación; y/o una especie de hoyo en el suelo donde echar chicha (bebida alcohólica obtenida por la fermentación de frutas, que aún se consume entre México y el norte de Chile) durante las ceremonias.

Fueron también los incas grandes observadores del universo, ante el cual se admiraban y asombraban. De acuerdo a los extensos y reconocidos estudios de la arqueóloga María Reich, las líneas de Nazca, en las pampas de Jumana, conjunto de figuras zoomorfas, fitomorfas y geométricas (líneas rectas, triángulos, espirales, un pájaro, una araña, un mono, flores), cuyo origen se desconoce, aunque parece ser que fueron elaboradas entre los años 100 y 800 d.C., son figuras que representan el movimiento de las estrellas y que permitían registrar las estaciones, algo muy necesario para el desarrollo de la agricultura. Científicos de la Universidad de Ciencias aplicadas de Dresde han confirmado los cálculos y las predicciones de la científica alemana, vinculando efectivamente las líneas de Nazca con posiciones de astros y constelaciones hace más de 2,000 años. Conocían y estudiaban muchos astros y constelaciones a las cuales rodeaban de mitos y leyendas que se volvían luego objeto de tradiciones. Ejemplos de ello son, la Yacana, la constelación oscura de la llama, cuyo largo cuello termina en las dos estrellas brillantes a y b Centauro, ojos del animal, la serpiente Machacuay, en la franja negra entre Sirius y la Cruz del Sur, y una perdiz, Yutu, en el conocido saco de carbón. Las Pléyades eran consideradas como la madre de todas las estrellas y merecían una veneración especial. Eran un indicador valioso para la plantación del maíz. Uno de los muros del patio central de Coricancha está orientado de tal manera que los científicos especulan que los Incas lo utilizaban como una mira para observar las Pléyades en el horizonte o determinar con precisión su salida heliacal. Un trazo sobre dicho muro habría sido una gran ayuda para entender conceptos claves de la cosmovisión andina; entre otras cosas, muestra la división masculina (a la izquierda) y femenina (a la derecha) del mundo; la división triple del cielo, tierra y mundo subterráneo; cuerpos celestes como el Sol, la Luna, Venus matutina y vespertina, posiblemente las estrellas de Orión (las tres Marías, Rigel y Betelgeuse), de la Cruz del Sur, y algunas constelaciones representando animales; y finalmente fenómenos naturales como relámpagos y arcoiris; elementos todos ellos constituyentes esenciales de su cosmovisión, como adelante se verá.

Los incas asociaban un valor ominoso a los fenómenos como eclipses y cometas, porque eran eventos escasos que interrumpían el orden natural del cielo. Particularmente, los eclipses del Sol generaban miedo y les inducía a la práctica de sacrificios para reconciliarse con el Sol enojado. Garcilazo de la Vega explica que los eclipses lunares eran considerados como una enfermedad del satélite, lo que podía ocasionar su caída sobre la tierra, lo cual trataban de evitar haciendo mucho ruido y haciendo ladrar a los perros, porque la leyenda decía 
que estos animales le habían hecho un favor a la luna, así que a cambio ella tenía que mejorarse para que dejen de estar tristes y ladrando.

Como en las otras culturas prehispánicas destacó en los incas también el calendario, un calendario anual solar.

Es muy claro, entonces, que como también en las otras culturas prehispánicas, la astronomía desarrolló un importante papel en la organización del Tahuantisuyu (las cuatro regiones unidas), y en el fortalecimiento de la autoridad del Inca. Los elementos anteriores, como ejemplos de su hacer cultural, confirman el enorme nivel de desarrollo de estos llamados hijos del Sol, cuyos pueblos se extendieron por todo el Perú, Ecuador, Bolivia, alguna parte del Brasil y del norte de Chile.

En cuanto a su cosmovisión ${ }^{18}$ se acepta que existieron dos versiones: Una, privativa de la élite, y otra destinada al vulgo. Prueban lo anterior el hecho que los templos eran muy exclusivos y destinados solo para el Inca y los sacerdotes, por lo que permanecían siempre cerrados y protegidos. Al margen de lo anterior, persiste una cosmovisión inca que se puede expresar ${ }^{19}$, de la forma siguiente:

La cosmovisión inca divide el espacio universal en tres suelos: El suelo de arriba, o cosmos, o Hanan Pacha; el suelo o plano de abajo, o la superficie de la tierra, o Kay Pacha o Hurin Pacha; y el suelo celestial, o la tierra interior, o Ukhu Pacha, o Hinan Pacha.

Las extensiones de cada suelo son bien definidas: La bóveda celeste ilimitada, el mundo objetivo real visible, y el plano invisible de las entrañas de la tierra, llamado también Ucu Pacha. Al Hurin Pacha, o mundo de la generación y corrupción de la vida y de la muerte, mundo de la superficie terrestre, se le atribuye un centro $u$ ombligo por donde pasan dos líneas imaginarias, en sentido horizontal y vertical, que dan origen a las cuatro grandes zonas de la tierra o puntos cardinales. El Hurin Pacha ofrece así una división en cuatro sectores, y de allí, como en los mayas, el simbolismo incaico del cuatro: la división del imperio en cuatro suyos, (Tehuantisuyo), que significa las cuatro partes del mundo, cuatro caminos, cuatro calles principales que salen del Cusco, cuatro fiestas solemnes, la principal de las cuales duraba cuatro días, cuatro señores orejones que constituían el Consejo en cada pueblo, cuatro quipucamayos en cada pueblo, etc.

18 Qosco, Religión Incásica, http://.qpsco.com/qosqoes/religión.html

19 M. L. Rivera de Tuesta, El pensamiento incaico, en Filosofía Iberoamericana en la época del encuentro, edición de Laureano Robles, Enciclopedia iberoamericana de filosofía, Ediciones Trotta, Consejo Superior de Investigaciones Científicas, Quinto Centenario, Madrid, España, 1992. 
Las creencias del pueblo inca procedieron de una larga tradición incaica, que se dice iniciada en el siglo II a.C., y que se simbolizaron en el Inti o Dios Sol. Todas las deidades eran subordinadas y creadas por un Dios invisible, eterno y todopoderoso que recibía el nombre de Wiracocha. Este trascendía los tres mundos de la cosmovisión, y por lo tanto, su morada no se ubicaba ni en el Hanan Pacha, o Mundo de Arriba, identificado como el espacio sideral, ni en la faz de la tierra misma, o Kay Pacha, ni en el Ukhu Pacha o mundo de abajo, identificado con el subsuelo. Todos los dioses, menos Wiracocha, moraban en el Hanan Pacha, y allá iban a parar también los espíritus de los difuntos nobles; de este mundo procedían los incas como hijos del Sol.

Entre los dioses más importantes ${ }^{20}$ había una diosa telúrica, Pachamama, la madre-tierra, identificada como una niña. Esta era la divinidad productora de alimentos, que respondía a su concepción dualista del mundo junto con la divinidad celeste, que, como ya se ha dicho, era Wiracocha, dios con características solares cuyos orígenes e importancia son aún objeto de discrepancia: No se sabe si era originalmente un dios tiahuanaco cuyas características solares fueron asimiladas por los incas y luego impuestas a los cuatro suyos del imperio, Collasuyo al sur, Contisuyo al oeste, Chinchaysuyo al norte y Antisuyo al este. El Sol es la fuente de vida en esas sociedades basadas en la agricultura, y por ende percibido como una deidad dadora de vida, como un dios creador o padre progenitor. Es necesario señalar que también tenían deidades con múltiples aspectos y capaces de transformación. Las huacas, por ejemplo, jugaban un rol preponderante en la religión como espacios sagrados ubicados en los diferentes ceques, en las 41 líneas que partían desde el templo del Sol, en el mismo centro de Cusco, la capital de Tawantisuyo y llegaban a los cuatro suyos.

Tratando de resumir los puntos principales de la cosmovisión de los Incas, que recogen toda la larga y hermosa tradición quechua, puede anotarse que:

1. Todo estaba dividido en lo masculino y lo femenino.

2. Existían relaciones fraternales con los elementos del entorno natural, característica esta, si bien ciertamente común a todas las culturas prehispánicas, muy acentuada en ellos.

3. Las personas se consideraban hermanos y hermanas de las rocas y de las montañas.

4. Todo en el cosmos estaba en equilibrio, el orden del cosmos era vital, simétrico. 
5. En el universo habían tres diferentes mundos: El Cosmos, Hanan pacha, La superficie de la tierra, Kay pacha, y La tierra interior, Ukhu pacha, equivalentes al mundo de arriba, la faz de la tierra y el mundo de abajo (el espacio sideral, la tierra misma y el subsuelo).

6. El espacio y el tiempo eran sagrados. La concepción del espacio era dualista, y se expresaba en una división del espacio horizontal en Hanan y Urin, el mundo de arriba y el mundo de abajo, respectivamente, cada una de las cuales se subdividía a su vez en otras dos partes, Hanan Pacha y Urin Pacha ( pacha $=$ tiempo = espacio); el tiempo a su vez era cíclico, y por ello, las diferentes edades del mundo. Antes de los incas hubo cuatro edades: Uari Wiracocha Runa, Uari Runa, Purun Runa y Auca Pacha Runa. Algunos críticos de la cultura inca tratan de identificar tales edades siguiendo la historia bíblica, identificando por ejemplo a los primeros hombres con los descendientes de Noé.

\section{5.- PARALELISMOS PREHISPÁNICOS CON LA ASTRONOMÍA Y LA COSMOLOGÍA DE LA GRECIA ANTIGUA.}

Es un objetivo importante en este trabajo, establecer de manera lo bastante general pero firme, el sorprendente paralelismo existente entre las visiones del mundo existentes en los pueblos prehispánicos de América y la astronomía y la cosmología de la Grecia antigua, así como también algunas diferencias.

Miguel León Portilla ${ }^{21}$ se plantea la reflexión de cómo los tlamatinime nahuatl llegaron a hacerse las mismas preguntas y a plantearse los mismos problemas que los que en otras partes del mundo habían sido objeto o continuaban siéndolo de la reflexión filosófica: La divinidad, el origen, ser y destino del hombre y del mundo. En la tercera categoría de las cuatro fuentes de estudio de las culturas prehispánicas que él establece, incluso, se identifican poemas que expresan creencias, dudas y problemas que pueden compararse a las de los presocráticos griegos.

Sorprendentemente, la similitud de conceptos y visiones es grande. Por ejemplo, con la cultura Náhuatl pueden citarse los siguientes:

1. Los mismos cuatro elementos de su pluralidad de esencias.

2. Una división del mundo en sectores masculino y femenino.

3. Un mundo y un universo estructurados jerárquicamente.

4. La noción clara y fundamental del movimiento, y con ello, de la

21 M. León Portilla, El pensamiento nahuatl, en Filosofía Iberoamericana en la época del encuentro, edición de Laureano Robles, Enciclopedia iberoamericana de filosofía, Ediciones Trotta, Consejo Superior de Investigaciones Científicas,, Quinto Centenario, Madrid, España, 1992 
tensión y la lucha, elementos estos claramente dialécticos.

5. Las nociones de mundos diferentes estructurados sobre la base de los conceptos de imperfección (corrupción) y perfección.

6. La necesidad de fundamentar el mundo sobre la base de una explicación racional del mismo.

7. Una estructura de pensamiento que problematiza fundamentalmente a Dios, al Mundo y al Hombre.

León Portilla ${ }^{22}$ establece otras categorías cosmológicas en los náhuatl, que yo considero son compartidas con la visión de los antiguos griegos, al margen de algunas diferencias:

a) La necesidad lógica de una fundamentación universal. A la pregunta ¿Qué es lo que hace estar las cosas en pie?, que equivale a la pregunta aristotélica por la raíz, por la esencia de las cosas, los náhuatl responden diciendo que Ometeotl, que está en los cielos y está en la tierra. Ometeotl es la raíz, la esencia de las cosas. Increíblemente se muestra aquí una enorme similitud con la explicación dada por la tradición cristiana.

b) La temporalización del espacio en edades, ciclos y elementos. La tierra no es estática. Sometida al influjo de las fuerzas cósmicas, viene a ser el campo donde estas actúan. Cuando se equilibran, deviene una edad, un Sol, y viven los macehuales, esto es, viven los hombres. Con el tiempo desaparece el equilibrio y sobreviene un cataclismo, que es lo que precisamente esperaban cuando llegaron los españoles. Los soles que han existido corresponden a los cuatro hijos de Ometeotl, los cuatro elementos, tierra, agua, aire y fuego, que son fuerzas cósmicas que irrumpen desde los cuatro rumbos del mundo. Aquí la similitud entre los estados de tensión y equilibrio existentes entre los cuatro elementos del mundo sublunar aristotélico.

c) Los rumbos del universo, es decir, las direcciones espaciales. Estos, como se ha visto, son cuatro, y sorprendentemente coinciden con nuestros cuatro puntos cardinales. Estos rumbos son aquellos por los cuales, el Sol, en su movimiento, nace, combate y muere todos los días.

d) La lucha. Las cuatro fuerzas cósmicas luchan, y cada elemento trata de prevalecer. La historia del cosmos avanza por ciclos producto de las luchas entre las fuerzas cósmicas. Se alternan entonces la lucha y la armonía. 
e) El movimiento. El quinto Sol, el Sol actual, en los náhuatl, equivalente al 4 ahau 8 cumku en los mayas, que significan el inicio del tiempo, al este espacializarse y entonces orientarse los años y los días hacia los cuatro rumbos del universo. En ese preciso día se pone en marcha la vida, se ordena todo, y el cosmos comienza a actuar de manera regular: el día y la noche se suceden, las estaciones se suceden, los dioses rigen el mundo, los hombres cumplen con su misión en la tierra. El Sol, pues, no solo ha creado la vida y el movimiento, sino que ha impuesto un orden fundamental en el devenir cósmico y humano. El siglo náhuatl es de 52 años, y a cada rumbo le corresponden 13 años. A cada año, a su vez, corresponde la influencia de uno de los rumbos, y él predomina. Así, al unirse el espacio y el tiempo, se compenetran y hacen posible la armonía de los dioses, las cuatro fuerzas cósmicas, y con esto se originan el movimiento del sol y de la vida. Esta entonces no es concebible sin el movimiento, y el movimiento a su vez no es concebible sin el espacio y el tiempo. Cada cuatro soles (cuatro grupos de trece años dominados por el influjo de cada uno de los rumbos), aparecerá un quinto Sol. Pero habrá, al final, un movimiento tan fuerte en la tierra, un cataclismo, en el que todo perecerá. Esto sucederá en un quinto Sol, esto es, en el actual.

f) Una semejanza importante entre náhuatl y mayas ${ }^{23}$ es su concepción del tiempo fundamental, cíclico y lineal, concepto que aunque se da en la realidad concreta de las antiguas culturas occidentales, no se expresa en ellas en esa forma. Estos prehispánicos concebían tres diferentes tiempos y en función de los mismos ordenaban sus vidas:

El tiempo fundamental, o tiempo perfecto, que es el tiempo de los orígenes, de la creación del cosmos y de la vida, esto es, el quinto sol de los náhuatl, o el 4 ahau 8 cumku de los mayas.

El tiempo cíclico, o tiempo sagrado, cuya expresión es el calendario, y que se vierte en sus sistemas astronómicos y adivinatorios. El ciclo nahuatl de 52 años, por ejemplo. En este, cuando se cumple cada ciclo, hay un desgaste de la energía vital por el paso del transcurrir temporal, y una sucesiva revitalización de las fuerzas que dan energía al cosmos.

Y el tiempo lineal, o tiempo de los hombres, en el cual se sitúan las acciones profanas de los hombres, haciendo uso del calendario, de la escritura, y del ordenamiento de las instituciones políticas estables.

Puede agregarse aquí el hecho de que para los náhuatl, los cuatro elementos eran considerados dioses, solo jerárquicamente situados bajo los dioses de la

23 E. Florescano, Concepciones de la Historia, en Filosofía Iberoamericana en la época del encuentro, edición de Laureano Robles, Enciclopedia iberoamericana de filosofía, Ediciones Trotta, Consejo Superior de Investigaciones Científicas, Quinto Centenario, Madrid, España, 1992. 
Providencia, Tezcatlipoca, del Sol, Tonatiuh, y de la Luna, Metztli. Quetzalcoatl, la serpiente emplumada, era el dios del aire; Tlaloc, el señor del paraíso, era el dios del agua; Xiuhteuctli era el dios del fuego; y Centeotl era la diosa de la tierra y del maíz.

¿No es acaso sorprendente la similitud de la concepción de los cuatro elementos y de la quinta esencia aristotélica, con esta concepción náhuatl de las cuatro fuerzas cósmicas y del quinto Sol en movimiento? ¿No es similar el enfoque dialéctico entre ambas? ¿No es sorprendentemente similar la concepción de los dos espacios en ambos, y de la idea de imperfección existente en el espacio horizontal náhuatl y el mundo sublunar aristotélico, así como la idea de perfección existente en el espacio vertical náhuatl y en el mundo supralunar aristotélico? ¿Y esa estratificación de las categorías espaciales, producto de una estratificación de las categorías cosmológicas mismas, que se presenta en ambas visiones?

E incluso, ¿no es sorprendente esta similitud en el hecho de compartir las concepciones del diluvio universal, de la confusión de las lenguas y de la dispersión de los pueblos tenida por ellos e igualmente por la religión y la cultura judío- cristiana, al margen, por supuesto, del cómo, del quién y del cuándo tales conceptos o hechos se originaron o se dieron?

Pero los náhuatl tienen dentro de su concepto cosmológico, un aporte todavía más fuerte, inmensamente más fuerte diría yo, que es el espacializar y temporalizar el universo, y más aun, el de espacializar el tiempo y temporalizar el espacio, constituyendo así un constructo espacio-temporal de cuatro dimensiones.

E incluso, una diferencia importante que considero necesario anotar: en su concepción del mundo, los náhuatl reconocen que ese mundo ha existido intermitentemente varias veces consecutivas, esto es, en cada Sol, y ha sido destruido igualmente varias veces por sendos cataclismos. Pero este aparente determinismo fatalista no es tal cuando ellos mismos consideran que los humanos, haciendo 'merecimiento', podían posponer ese trágico final. Es decir, la cosmovisión náhuatl concede cierto grado de libertad al hombre, y le otorga a este un rol determinado e importante dentro de su papel en el cosmos. Esta cuestión, en los filósofos de la antigua Grecia, no se sostiene con tanta claridad.

Además, si bien los hombres, los macehuales, debían buscar llegar a la ciudad de la luz, esto es, buscaban trascender, debían también consagrarse en la tierra, imitando al Dios Dual, repitiendo en pequeño en la tierra la acción del que todo engendra y concibe, atributo supremo del Dios de la Dualidad, con lo cual conforman una teoría de la inmanencia- trascendencia sorprendentemente 
parecida a la sostenida por el judeo-cristianismo, que incluso podría decirse que supera a la griega.

Es indudable que entre las culturas náhuatl, maya y quechua existen sobradas y reconocidas similitudes y muy, pero muy pocas diferencias. Antonio Caso, el gran filósofo mexicano, ha sustentado la tesis de que la astronomía y la matemática, así como los sistemas de cómputo cronológico y calendárico, eran comunes en toda Mesoamérica. Hay un alto grado de semejanza y similitud entre el pensamiento de estas culturas y el de la antigua Grecia, aunque debe señalarse que hay visiones parciales no sostenidas por ellos. También en su cosmovisión se parte de un universo infinito en donde existe una pluralidad de esencias. En la misma forma, se trata de mundos jerárquicos, en donde se da ya la noción del movimiento. Se expresan ideas sobre la perfección y la imperfección que son trasladadas a la realidad. En los mayas, el universo está también espaciotemporalizado, se habla también de tres mundos, (cuestión no contemplada en los griegos), de una visión cromática de la realidad (en la misma forma no encontrada en los griegos), de mundos localizados en espacios verticales y horizontales (tampoco es así en los griegos), de un mundo creado (nueva diferencia). Pero lo más importante es que tanto los griegos como los náhuatl y los mayas buscan una explicación del mundo sobre bases racionales, tratan de encontrar una fundamentación lógica del universo, y se encuentran empeñados en establecer esa hasta ahora no discutible relación entre los fenómenos terrestres, las manifestaciones de esa esencia múltiple, con los del universo sideral.

Debe decirse que los antiguos griegos recogen una herencia de por lo menos cuatro siglos sobre la cual hace descansar su cosmovisión, y en general, toda su filosofía; y que estas se sostienen casi paradigmáticamente hasta por lo menos los albores de la filosofía moderna, esto es, el siglo XVII. Aún en el pleno estadio de la post-modernidad y de la nueva ciencia en el que ahora nos encontramos, el hombre sigue siendo físicamente newtoniano, geométricamente euclidiano, y lógicamente aristotélico. Los náhuatl, por su parte, se extendieron desde 20 siglos antes de Cristo hasta 16 después de Cristo. Y se dice que los mayas y los incas ya aparecían dos siglos antes de Cristo. Este grueso sedimento les permitió acumular una cultura que ha admirado al mundo. Ciertamente sigue siendo una incógnita ese persistente ¿cómo lo hicieron?, sobre el cual se acumulan muchas posibilidades de respuesta. Van Newman, estudioso de las culturas prehispánicas, se las explica, acudiendo al expediente y al argumento ligero y poco fundamentado de las influencias y presencias extraterrestres. El sabio Barberena ${ }^{24}$, afirma haber siempre creído que los náhuatl y los mayas fueron originarios del viejo mundo, esto es, de Europa, habiendo llegado los

24 S. I. Barberena, Historia de El Salvador, Época antigua y de la Conquista, Tomo I, Ministerio de Educación, Dirección General de Publicaciones, Tercera Edición, San Salvador, El Salvador, C. A., 1977 
primeros por el pacífico y los segundos por el atlántico; según este historiador, las migraciones hacia los náhuatl fueron muchas y sucesivas, no así las de los mayas, quienes aparentemente fueron producto de una sola migración, siempre lejana pero posterior a las de los nahuatl. Y concluye el sabio diciendo que las cosmovisiones de ambas culturas no son otra cosa que el producto de mitos y leyendas muy poco respaldadas por la realidad, negando o relativizando así lo que tanto se afirma en cuanto al esplendor de las mismas. Pero, anoto, ¿Acaso no hubo un formidable mundo mítico en la cultura occidental, particularmente en la griega antigua? Porque, por más que se confirme el reclamo pitagórico del rechazo a Homero y a Hesíodo, siempre estos antecedentes, consciente e inconscientemente, pesaron en la filosofía posterior que se afincó en el logos heracliteano. Y por otro lado, ¿acaso no están allí todavía elocuentes muestras de esas civilizaciones, las líneas de Nazca que tanto impactaron a Von Newman, y Teotihuacan, y Tula, y Cusco, y todos los teocallis que ocultaron después los templos católicos edificados sobre ellos, sólo para citar algunas? Trabulse, por ejemplo ${ }^{25}$, opina al contrario de Barberena, que el nivel cultural de los pueblos mesoamericanos a la llegada de los españoles era alto, a tal grado que ello obligaría a estos a modificar sus esquemas mentales acerca del mundo que habitaban.

Debe considerarse que a pesar de la fuertemente sustentada tesis de la autenticidad del hombre americano sostenida sobre todo por el antropólogo argentino-italiano Florentino Ameghino, lo que predomina al momento es que los primitivos americanos vinieron de otro continente, probablemente de Asia. La tesis inmigracionista, como apunta Luis Alberto Sánchez ${ }^{26}$ se refuerza con muchos estudios, investigaciones e incluso tradiciones como las de que habla el Inca Garcilazo en sus Comentarios Reales, las toponimias incas-zapotecas, las analogías de algunos monumentos, algunas similitudes en las estructuras sociales entre mexicas y chinos, similitudes también entre las conformaciones craneanas y signos fisionómicos entre asiáticos y americanos, e incluso, las refutaciones científicas hechas por sabios como A. Hrdlicka, de la Smithsonian Institution ${ }^{27}$, quien, sobre la base de investigaciones de antropología física, refuta la tesis autoctonista, y afirma que el hombre llega a América en un estado de desarrollo superior al del paleolítico de Europa, posición que comparten otros científicos como Paul Rivet, el mexicano Pablo Martínez del Río, y Franz Boaz.

Si se acepta la tesis inmigracionista, pudiera pensarse de alguna manera que los paralelismos entre las cosmovisiones que aquí se vienen comentando tienen su explicación en ese origen común que pudiera haber existido entre el hombre americano y el asiático, e incluso, el europeo; o, en todo caso, al contacto que pudiera haber existido entre ellos.

25 E. Trabulse, Historia de la Ciencia en México, versión abreviada, CONACYT, Fondo de Cultura Económica, Primera Re-Impresión, México, 1997

26 L. A. Sánchez, Historia General de América, tomo I. Sexta edición corregida y puesta al día, Ediciones Ercilla, 1956

27 R. E. Latchman, Prehistoria Chilena, pp. 11, Santiago, Chile, 1936 
Algunas opiniones adicionales, sin embargo, deberían ser tomadas en consideración. Por ejemplo, la opinión que el francés Raúl d'Harcourt ${ }^{28}$ emite en el sentido que si el americano no es autóctono, llegó al Nuevo Mundo con conocimientos y técnicas sencillos, propios de la edad paleolítica. Las adquisiciones posteriores se las debe a él mismo, a su genio inventivo, que le permitió levantar poco a poco por sus propios medios un monumento sólido y bello, opinión que hace ver lo complejo y aun nada claro que es este asunto del cómo pudieron darse los tales paralelismos entre las cosmovisiones de las culturas prehispánicas con otras, particularmente la de los griegos antiguos.

Como dice Laureano Robles ${ }^{29}$ en la presentación del excelente libro Filosofía Iberoamericana en la época del encuentro, "la cultura americana forma parte de la cultura griega y europea. Pero a condición de que admitamos que la cultura europea, a partir del descubrimiento de América y del encuentro de ambos mundos, ya no es totalmente griega, como tampoco es totalmente europea la cultura del otro lado del mar. América va recuperando toda una serie de elementos de su pasado precolombino, que tiene que ir 'in crescendo" con los años, no sólo para enriquecerla a ella, sino también a estas tierras de Europa, del viejo continente, que tantos cambios ha sentido en su piel a partir de aquel hecho del "encuentro" ".

Este asunto, considero, merece ser estudiado.

Es de citar que en las tres culturas aparece una clara división del mundo en lo masculino y lo femenino: Ometeotl en el treceavo cielo, que se desdobla en dos deidades, masculina y femenina; Manco Capac y Mama Ocllo como producto del desdoblamiento del rey Inti o rey Sol, Wiracocha. Y algo que se ha dicho ya: Una estructura de pensamiento que problematiza fundamentalmente a Dios, al Mundo y al hombre.

Bien el tema da para investigaciones y estudios futuros.

En cuanto a los incas, las similitudes con el mundo antiguo griego se sienten más tenues. Sí hay una tendencia en ellos a espaciotemporalizar el universo, así como hay también una clara noción del movimiento. Sí expresan visiones de un universo estratificado y jerarquizado, y disperso hacia los cuatro puntos cardinales. Es, asimismo, una visión geocéntrica, expresada y desarrollada en tres mundos.

Pero los incas, aunque comparten el sentido de un universo infinito, no comparten la idea de la creación, ni es claro en ellos que se haya formado por una pluralidad de esencias. Cuando se habla de su origen, es un lugar común sostener que provienen de migraciones asiáticas a través del pacífico. Debe

28 R. d'Harcourt, América antes de Colón, pp. 8, Madrid, 1926

29 L. Robles, Presentación, en Filosofía Iberoamericana en la época del encuentro, edición de L. Robles, Enciclopedia iberoa- mericana de filosofía, Ediciones Trotta, Consejo Superior de Investigaciones Científicas, Quinto Centenario, Madrid, España, 1992 
decirse que su toponimia presenta diferencias y similitudes con las náhuatl y maya, y que en ellos la visión agrícola del desarrollo fue bastante más acentuada que en las otras culturas.

\section{6.- BIBLIOGRAFÍA.}

Luis Alberto Sánchez, Historia General de América, tomo I. Sexta edición corregida y puesta al día, Ediciones Ercilla, 1956.

Angel Rosemblatt, Población Indígena de América, revista Tierra Firme, núm. 8, pp. 110. Madrid, España, 1935.

De las Casas, De la Destrucción de las Indias.

Francisco Javier Clavijero, Setima disertación, Historia Antigua de México, libro X, segunda edición. Editorial Porrúa, S. a., México, 1968.

http: / /oncetv-ipn.net/sacbe/mundo/el-cosmos-maya/

Máxime Boccas, Astronomía Incaica: el misterio sigue ...., http://www.ctio. Noao-edu/-boccas/astro2000-2.html.

Qosco, Religión Incásica, http://.qpsco.com/qosqoes/religión.html

Cosmovisión andina en el relato warma kuyay de José María Arguedas, http: // sincronia.cuchs.udg.mx/arguedas.htm

Miguel León Portilla, La Filosofía Nahuatl estudiada en sus fuentes, $3^{\circ}$ Edición, UNAM, México, 1966.

Santiago I. Barberena, Historia de El Salvador, Época antigua y de la Conquista, Tomo I, Ministerio de Educación, Dirección General de Publicaciones, Tercera Edición, San Salvador, El Salvador, C. A., 1977.

Ana Llamazares \& Carlos Martínez Sarasola, Convergencias: Nuevos Paradigmas y Cosmovisión Indígena, fundación Desde América, http://www. desdeamerica.org.ar/ArtyTex/articulos/cnuevosparadigmas.htm

Juan de Torquemada, Monarquía Indiana, Madrid, 1614.

Juan Gregorio García, Tratado sobre el origen de los indios, Valencia, 1607; Madrid, 1729.

Francisco Javier Clavijero, Historia Antigua de México, libros I a VI, Segunda edición, Editorial Porrúa, S. A., México, 1968. 
Ricardo E. Latchman, Prehistoria Chilena, pp. 11, Santiago, Chile, 1936.

Raúl d’Harcourt, América antes de Colón, pp. 8, Madrid, 1926.

J. Gallo, E. Anfossi, Cosmografía, Editorial Progreso, S. A., Séptima Edición, $1^{\text {a }}$. Reimpresión, México, 1980.

Javier Tapia Rodríguez, Leyenda y misterio de los aztecas, Edicomunicación, S. A., Barcelona, España, 1977.

José Alcina Franch, Los Aztecas, Biblioteca de Historia, Talleres Gráficos Peñarola, S. A., Madrid, España.

Miguel León Portilla, El pensamiento nahuatl, en Filosofía Iberoamericana en la época del encuentro, edición de Laureano Robles, Enciclopedia iberoamericana de filosofía, Ediciones Trotta, Consejo Superior de Investigaciones Científicas, , Quinto Centenario, Madrid, España, 1992.

Laureano Robles, Presentación, en Filosofía Iberoamericana en la época del encuentro, edición de Laureano Robles, Enciclopedia iberoa- mericana de filosofía, Ediciones Trotta, Consejo Superior de Investigaciones Científicas, Quinto Centenario, Madrid, España, 1992.

Mercedes de la Garza, El pensamiento maya, en Filosofía Iberoamericana en la época del encuentro, edición de Laureano Robles, Enciclopedia iberoamericana de filosofía, Ediciones Trotta, Consejo Superior de Investigaciones Científicas, Quinto Centenario, Madrid, España, 1992.

María Luisa Rivera de Tuesta, El pensamiento incaico, en Filosofía Iberoamericana en la época del encuentro, edición de Laureano Robles, Enciclopedia iberoamericana de filosofía, Ediciones Trotta, Consejo Superior de Investigaciones Científicas, Quinto Centenario, Madrid, España, 1992.

Enrique Florescano, Concepciones de la Historia, en Filosofía Iberoamericana en la época del encuentro, edición de Laureano Robles, Enciclopedia iberoamericana de filosofía, Ediciones Trotta, Consejo Superior de Investigaciones Científicas, Quinto Centenario, Madrid, España, 1992.

Elías Trabulse, Historia de la Ciencia en México, versión abreviada, CONACYT, Fondo de Cultura Económica, Primera Re-Impresión, México, 1997. 